\title{
Open versus minimally invasive surgery for suspected adrenocortical carcinoma
}

\author{
Dylan M. Buller, Alex M. Hennessey, Benjamin T. Ristau \\ ${ }^{1}$ Division of Urology, UConn Health, Farmington, CT, USA \\ Contributions: (I) Conception and design: All authors; (II) Administrative support: None; (III) Provision of study materials or patients: None; (IV) \\ Collection and assembly of data: All authors; (V) Data analysis and interpretation: All authors; (VI) Manuscript writing: All authors; (VII) Final \\ approval of manuscript: All authors. \\ Correspondence to: Benjamin T. Ristau, MD, MHA. Assistant Professor of Surgery, Surgical Director of Urologic Oncology, Division of Urology, \\ UConn Health, 263 Farmington Avenue, Farmington, CT 06030, USA. Email: benristaumd@gmail.com.
}

\begin{abstract}
Adrenocortical carcinoma (ACC) is a rare malignancy with a poor prognosis. Although laparoscopy has been widely adopted for management of benign adrenal tumors, minimally invasive surgery for ACC remains controversial. Retrospective analyses, frequently with fewer than one hundred participants, comprise the majority of the literature. High-quality data regarding the optimal surgical approach for ACC are lacking due to the rarity of the disease and the fact that determination of tumor type (e.g., adenoma or carcinoma) is determined after adrenalectomy, since adrenal tumors are generally not biopsied. While the benefits of minimally invasive surgery including lower intra-operative blood loss and decreased hospital length-of-stay have been consistently demonstrated, clinical equipoise for long-term survival and recurrence outcomes between open and minimally invasive adrenalectomy (MIA) remains. This review examines retrospective studies that directly compare patients with ACC who underwent either open or laparoscopic adrenalectomy, and considers these findings in the context of current guideline recommendations for surgical management of ACC.
\end{abstract}

Keywords: Adrenocortical carcinoma (ACC); adrenalectomy; laparoscopy; robotic surgery; survival outcomes

Submitted Jun 05, 2019. Accepted for publication Dec 11, 2019.

doi: $10.21037 /$ tau.2020.01.11

View this article at: http://dx.doi.org/10.21037/tau.2020.01.11

\section{Incidence and clinical presentation of adrenocortical carcinoma (ACC)}

Incidental discovery of adrenal tumors is common and occurs in up to $7 \%$ of patients who undergo cross-sectional imaging for other reasons (1). The vast majority of these adrenal "incidentalomas" are benign, nonfunctioning adenomas. ACC itself is quite rare with an incidence of only 1-2 cases per million per year (2). ACC occurs slightly more often in women compared to men, with a ratio of approximately 1.5:1 (3). Though it has been diagnosed at any age, peak incidences occur in both the first half of the first decade of life, and the fourth and fifth decades of life $(4,5)$. Autonomous steroid production, such as hypercortisolism (Cushing's syndrome) or androgen excess, is present in around $60 \%$ of patients with ACC (4-7). The diagnosis of ACC is often presumptive based on imaging (CT or MRI) and hormonal workup and confirmed postoperatively on surgical pathology (3). Biopsy of lesions concerning for ACC is not recommended due to the potential for tumor spillage.

\section{Imaging characteristics of ACCs}

In assessing adrenal tumors, certain imaging characteristics are helpful in stratifying risk of malignancy. On CT imaging, ACCs are typically seen as large, heterogeneous suprarenal masses. Increasing tumor size is the most 
Table 1 ENSAT/AJCC staging classification and associated 5-year disease-specific survival $^{\dagger}$

\begin{tabular}{|c|c|c|c|c|}
\hline Stage & & & & 5-year survival \\
\hline \multirow[t]{3}{*}{ Stage I } & & $\mathrm{T} 1$ & & $82 \%$ \\
\hline & & NO & & \\
\hline & & MO & & \\
\hline \multirow[t]{3}{*}{ Stage II } & & $\mathrm{T} 2$ & & $61 \%$ \\
\hline & & No & & \\
\hline & & MO & & \\
\hline \multirow[t]{3}{*}{ Stage III } & T1-2 & or & T3-4 & $50 \%$ \\
\hline & $\mathrm{N} 1$ & & No-1 & \\
\hline & MO & & MO & \\
\hline \multirow[t]{3}{*}{ Stage IV } & & T any & & $13 \%$ \\
\hline & & $\mathrm{N}$ any & & \\
\hline & & M1 & & \\
\hline
\end{tabular}

\begin{abstract}
${ }^{\dagger}$, staging classification and 5-year survival data from Fassnacht et al. (20). 'Survival' refers to disease-specific survival. T1, tumor $\leq 5 \mathrm{~cm}$; T2, tumor $>5 \mathrm{~cm}$; T3, tumor invasion of surrounding tissue; T4, tumor invasion of adjacent organs or tumor thrombus in vena cava or renal vein; N0, no lymph node positivity; N1, lymph node positivity; M0, no distant metastases; M1, distant metastases.
\end{abstract}

commonly cited risk factor for ACC (8). Whereas only $2 \%$ of adrenal incidentalomas $4 \mathrm{~cm}$ or less are ACC, one quarter of incidental adrenal tumors larger than $6 \mathrm{~cm}$ have been found to be ACC $(5,9)$. One large study found that the risk of an adrenal cortical tumor being ACC is $10 \%$ when $\geq 4 \mathrm{~cm}$, $19 \%$ when $\geq 6 \mathrm{~cm}$, and $47 \%$ when $\geq 8 \mathrm{~cm} \mathrm{(10).} \mathrm{Another}$ study found $31 / 37$ (84\%) of adrenal cortical lesions $>8 \mathrm{~cm}$ to be ACC, while only 6/37 (16\%) were benign adenomas $(\mathrm{P}<0.01)(11)$. Most surgeons agree that non-functioning tumors less than $4 \mathrm{~cm}$ can be observed while tumors greater than $6 \mathrm{~cm}$ (except for asymptomatic myelolipomas) should be resected regardless of hormonal production status. The management of tumors between $4-6 \mathrm{~cm}$ is less clear and shared-decision making should be employed with patients to determine the possible need for resection (12).

Adrenal mass density characteristics on CT scan can also be used to help differentiate adenomas from suspected ACCs. The vast majority of adrenal masses measuring less than 10 Hounsfield units on non-contrast imaging represent adenomas (sensitivity $71 \%$; specificity of $98 \%$ for adenoma) (13). Though most ACCs measure greater than 10 Hounsfield units on non-contrast imaging, use of this criterion alone to diagnose ACC results in a high false positive rate, with reported specificities as low as $58 \%$ $(5,14,15)$. ACCs can further be distinguished from benign adrenal adenomas by their slower contrast washout (14). Unlike adenomas, which demonstrate both rapid uptake and washout of contrast on CT imaging, ACCs and other nonadenomatous lesions have a delayed contrast washout. In general, thresholds of $60 \%$ contrast enhancement washout and $40 \%$ relative contrast enhancement washout have been able to distinguish adenomas from non-adenomas, including ACC, with $92-100 \%$ sensitivity and $95-100 \%$ specificity (14,16-18). It should be noted that most of these imaging analyses have compared washout characteristics between adenomas and non-adenomas, and not explicitly adrenal adenomas from ACCs. One study examining washout characteristics of ACCs only found that out of 17 patients with ACCs, $71 \%$ had $\leq 60 \%$ contrast enhancement washout and $82 \%$ had $\leq 40 \%$ relative contrast enhancement washout using a 15-min delay (14). Therefore, some caution should be used relying solely on washout characteristics to "rule out" ACC.

Calcification and necrosis are common features of ACCs. Calcifications are observed in up to $37 \%$ of patients with ACC (14). They are typically located centrally and can be identified on routine pre-operative imaging $(5,14)$. Moreover, ACCs often have central areas of hemorrhage and necrosis, and therefore demonstrate more peripheral than central enhancement with contrast administration (19).

Since ACCs are commonly large at the time of diagnosis, invasion of adjacent organs and the venous system is not unusual. In an imaging-focused retrospective study, seven out of 41 patients with ACC (17\%) were found to have invasion into adjacent organs: two with liver invasion, two with kidney invasion, two with combined liver-kidney invasion, and one with combined pancreas, stomach, and diaphragm invasion (14). In the same retrospective study, 6 out of 41 patients $(15 \%)$ were found to have ACC extension and associated thrombus in the inferior vena cava (IVC) (14).

\section{Staging in ACC}

Staging for ACC is based on the European Network for the Study of Adrenal Tumors (ENSAT) and American Joint Committee on Cancer (AJCC) staging system (Table 1) $(20,21)$. ACC is classified into one of four stages. Broadly, stages I and II disease are confined to the adrenal gland, with a cutoff of $5 \mathrm{~cm}$ differentiating Stage I from Stage II disease. Stage III and IV ACC represent lymph node 
positivity (stage III or IV), local invasion (stage III or IV), or metastatic disease (stage IV). This staging system has been validated using data derived from 573 patients in 16 Surveillance, Epidemiology and End Results (SEER) registries (22). This validation confirmed the prognostic superiority of ENSAT over its predecessor, the International Union Against Cancer (UICC) staging system, which failed to differentiate prognostic implications of stage II versus stage III ACC $(20,22)$.

\section{Pre-operative workup for suspected ACC}

The European Society of Endocrine Surgeons (ESES) and European Network for the Study of Adrenal Tumours (ENSAT) have published guidelines for the pre-operative management of adrenal masses that are suspected to be ACC (19). Although the low overall quality of evidence due to the lack of prospective or randomized studies is acknowledged, the authors compiled consensus recommendations in light of the available evidence.

In taking a history, patients should be evaluated for symptoms associated with excess hormone production $(5,7,23)$ and symptomatic compression due to the large size of a mass $(5,7,23,24)$. A past medical history of malignancy is important since some adrenal tumors may represent metastases from another primary cancer. Lastly, a thorough family history should be obtained to assess for familial cancers and help guide the need for genetic assessment (25-28).

A full electrolyte and hormonal evaluation are recommended. Plasma and urinary metanephrines are checked to assess for the possibility of a pheochromocytoma, which carries its own unique clinical and operative management considerations (19). Additionally, the guidelines recommend biochemical assessment of steroid production (sex steroids and their precursors, aldosterone, and cortisol) as functional status of the tumor may necessitate post-operative steroid replacement. A prospective study is underway to determine the utility of 24-hour urine steroid profiling using mass spectrometry (29).

Pre-operative imaging recommendations for adrenal tumors are intended to identify those that are more likely to be malignancies, as well as to guide operative management. For suspected ACC, contrast-enhanced CT of the chest and abdomen within 6 weeks of surgery is recommended to identify characteristics of the tumor, lymph node involvement, and to assess for intravascular thrombus or invasion of the tumor into local structures. The guidelines also include gadolinium contrast-enhanced MRI as an essential component of an adrenal tumor workup if its risk of malignancy cannot be determined on CT alone. MRI is also more sensitive than CT for detection of tumor thrombus, vascular invasion, or liver involvement $(5,30)$.

Advanced imaging studies to accurately stage the disease and evaluate for distant metastasis can be used. $\left[{ }^{18} \mathrm{~F}\right]$ flurodeoxyglucose- (FDG-) PET is recommended within 6 weeks of adrenalectomy for adrenal tumors suspected to be ACC. Adrenal tumors that demonstrate FDG-avidity include ACC (31,32), pheochromocytomas (33), and some adrenal adenomas (34), though adenomas may have lower uptake when uptake is present. The specificity of FDGPET for ACC in a series of 77 patients was $88 \%$ when using a maximum standardized uptake value cutoff of 1.34 (31); therefore, it is best utilized to stage and follow the trajectory of the disease after surgical intervention. $\left[{ }^{11} \mathrm{C}\right]$ metomidate and $\left[{ }^{123} \mathrm{I}\right]$ iodometomidate are more specific for adrenocortical cells but they are limited by clinical availability (35) and an inability to distinguish between benign and malignant lesions.

\section{Survival outcomes in patients with ACC}

The rarity of this malignancy complicates precise assessment of outcomes. Prognosis is correlated with surgical margin status following resection and stage of disease at the time of diagnosis (6,36-44). In one study, recurrence-free survival (RFS) was as low as $18 \%$ at median follow-up of 88 months, with a median time to recurrence of 13 months (38). Surgical margin status is a critical factor associated with recurrence since R0 resection of ACC confers a decreased risk of recurrent disease compared to R1 or $\mathrm{R} 2$ resection (39,45-50). A review of 3,982 patients with ACC from the National Cancer Data Base found adjusted hazard ratios for 5-year survival of 1.81 (95\% CI, 1.44-2.27) for positive microscopic margins and 2.06 (95\% CI, 1.742.43) for positive macroscopic margins when compared to R0 resection status (39). Five-year overall survival (OS) rates range from $15 \%$ to $60 \%$, with as high as $84 \% 5$-year OS for stage I disease compared to only $18 \%$ survival for stage IV disease (20,39,46,51-56). Interestingly, the US ACC study group recently reported that patients with incidentally discovered ACC may present at an earlier stage compared to patients with functional and symptomatic ACC leading to potentially improved recurrence free survival for incidentally discovered tumors (57). Nonetheless, ACC is often discovered at advanced stages with approximately $70 \%$ of tumors stage II or greater at the time of diagnosis. 
Advanced stage at diagnosis and a lack of effective systemic therapy options contribute to its poor overall prognosis $(36,58,59)$.

\section{Surgical management of ACC}

Open adrenalectomy $(\mathrm{OA})$ is the gold standard treatment for suspected ACC when technically feasible $(19,58)$. The past 20 years have witnessed the advent and rapid expansion of minimally invasive surgery in surgical oncology. In order of importance, the priorities during surgery for suspected ACC are (I) oncologic control and (II) application of a minimally invasive approach. The first report of laparoscopic adrenalectomy (LA) for ACC was published in 1993 (60). Other early case reports and small case series began reporting on the role of laparoscopy in adrenalectomy for ACC in the late 1990s. These small studies and single patient reports yielded results that were split between optimism for a new, minimally invasive approach to a historically open procedure (61-65), and apprehension due to concern for increased risks of locoregional recurrence and peritoneal carcinomatosis (66-72).

\section{Studies in which the data favor open adrenalectomy}

Despite initial enthusiasm for LA, a number of studies have published data favoring an OA over LA in patients with suspected ACC (Table 2) (70,73-80). The first of these analyzed results from 159 patients with ACC, though only 6 underwent LA against 153 undergoing OA (70). Followup data were available for 133 patients in the OA group, $86 \%$ of whom had experienced recurrence at a median follow-up of 28 months. At follow-up, all six patients who had undergone LA had experienced recurrence. Additionally, whereas only 11 of 133 patients (8\%) in the OA group had peritoneal carcinomatosis present at the time of initial failure, it was present in five out of six patients in the LA group (83\%), leading the authors to conclude that OA is superior to LA for suspected ACC (70).

Data from five series were published between 2010 and 2013. In 2010, Leboulleux et al. published retrospective data on 64 patients, 58 of whom underwent OA versus 6 who underwent LA (75). While the sample of patients undergoing LA was low, LA once again portended an increased risk of peritoneal carcinomatosis $(67 \%$ in the LA group compared to a $27 \%$ in the OA group at four years after adrenalectomy). After analysis of other metrics such as tumor size and stage, LA was found to be the only variable associated with peritoneal carcinomatosis, with a 4-year hazard ratio (HR) of 3.8 (95\% CI, 1.2-12.3).

Another study published in 2010, from Miller et al., compared retrospective outcomes of 88 patients with stage I-III ACC (76). Slightly more LA cases were included in this series, with 71 patients having undergone $\mathrm{OA}$ versus 17 undergoing LA. This study found that although tumor size was unbalanced between groups and were more favorable in the LA group (median tumor size was $7.0 \mathrm{~cm}$ in LA group versus $12.3 \mathrm{~cm}$ in OA group), outcomes favored OA nonetheless. Significant findings included a longer mean time to local recurrence $(19.2 \pm 37.5$ versus $9.6 \pm 14$ months, $\mathrm{P}<0.005)$ and a lower positive margin or intraoperative tumor spill rate $(18 \%$ versus $50 \%, \mathrm{P}=0.01)$ in the OA group compared to the LA group.

In 2012, Miller et al. published an update on these 88 patients and included 68 new patients, with stages I-III ACC who had undergone either LA or OA (77). Several important outcomes in this study favored an open over laparoscopic approach to adrenalectomy for suspected ACC. Positive margins, an important prognostic indicator for patients after adrenalectomy, were more likely to be present after LA compared to after OA (30\% versus $16 \%$, $\mathrm{P}=0.04)$. Recurrence in the tumor bed occurred faster in patients undergoing LA compared to patients undergoing OA (mean time: 11.7 versus 30.5 months, $\mathrm{P}=0.002$ ). This pattern persisted for recurrence in any distant location (mean time: 17.6 after LA vs. 30.5 months after $\mathrm{OA}, \mathrm{P}=0.002$ ). Mean OS was significantly longer in patients with stage II ACC who underwent OA compared to LA (103.1 versus 50.9 months, $\mathrm{P}=0.002)$. A critical finding from Miller et al. was the discovery that $31 \%$ of clinical stage II patients were upstaged to stage III based on post-operative pathology. This finding has implications for those advocating tumor stage I or II as a criterion for choosing LA over OA for ACC (24,81-85), as evidence suggest that up to one in three patients selected for LA based on their clinical stage II are understaged, and may be inappropriate candidates for LA.

In 2013, Mir et al. reported retrospective data on 44 patients, 26 of whom had undergone OA, and 18 of whom had undergone LA for stages I-IV ACC (78). Similar to the 2010 Miller study, median tumor size was larger in the OA group compared to the LA group (13 versus $7 \mathrm{~cm}$, $\mathrm{P}=0.001)(76,78)$. In addition, patients in the OA group had more advanced tumors at baseline when compared to the LA group (62\% stages III-IV versus $11 \%$ stages III-IV, $\mathrm{P}=0.001)$. Despite the poorer pre-operative tumor profiles 

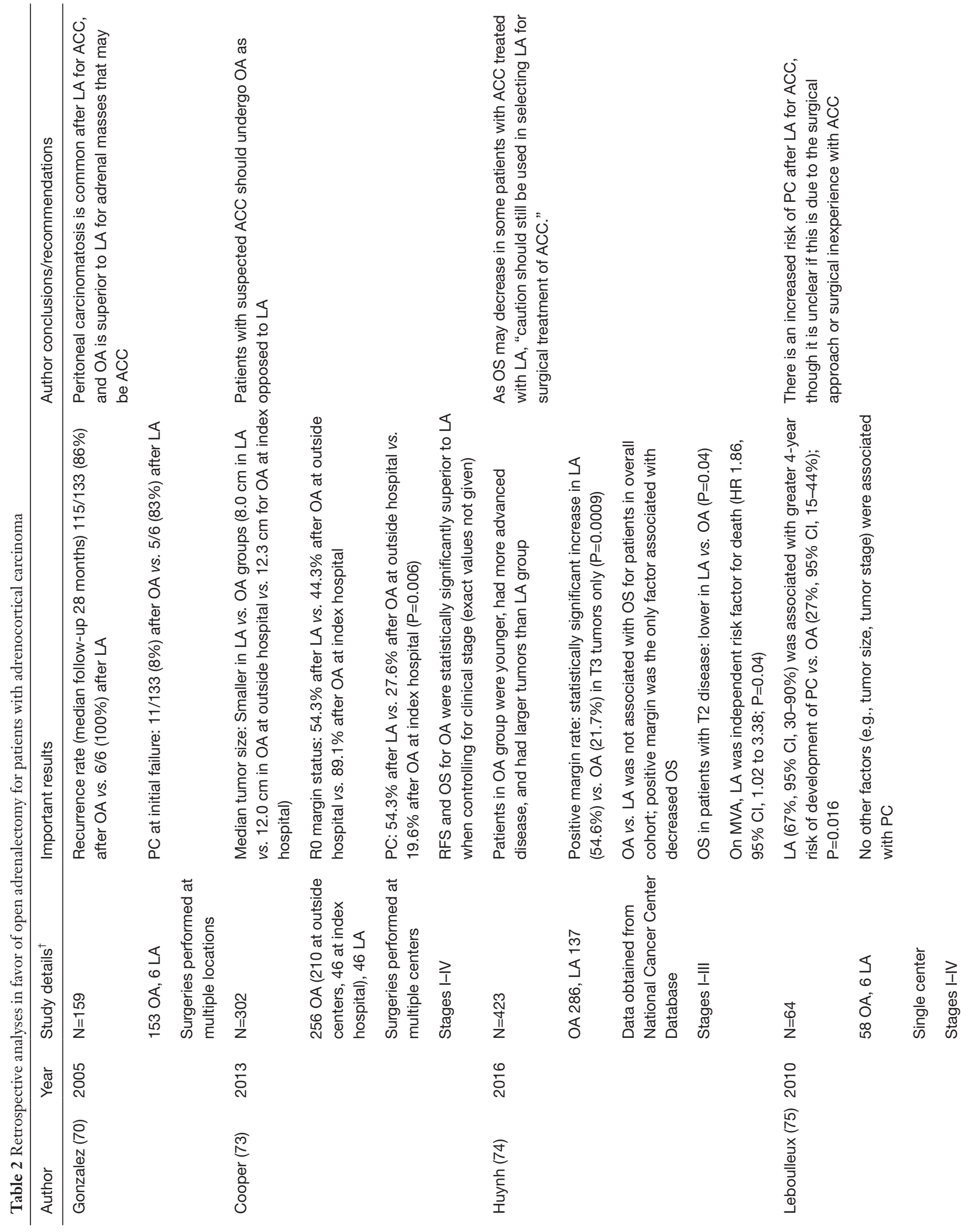

离 

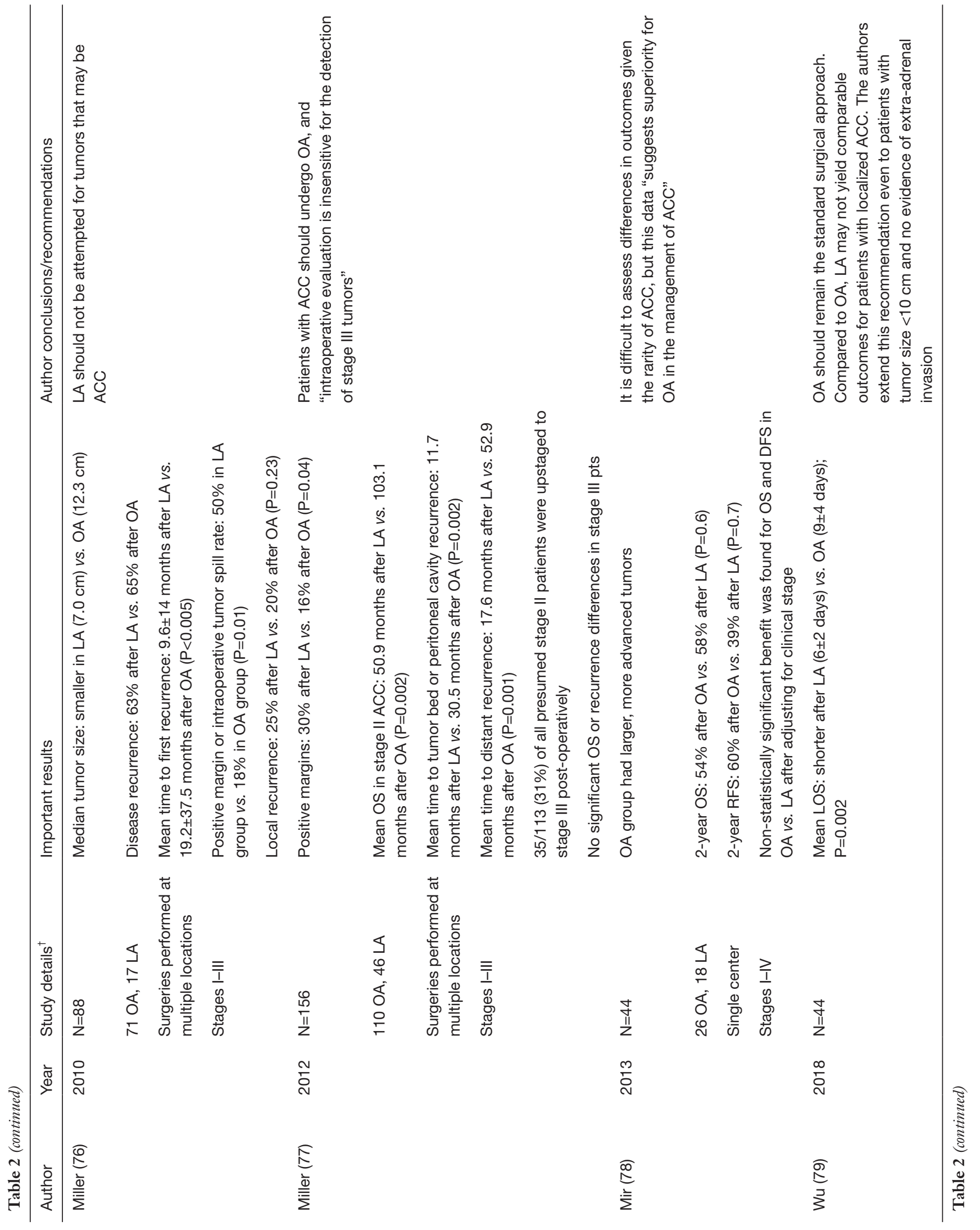

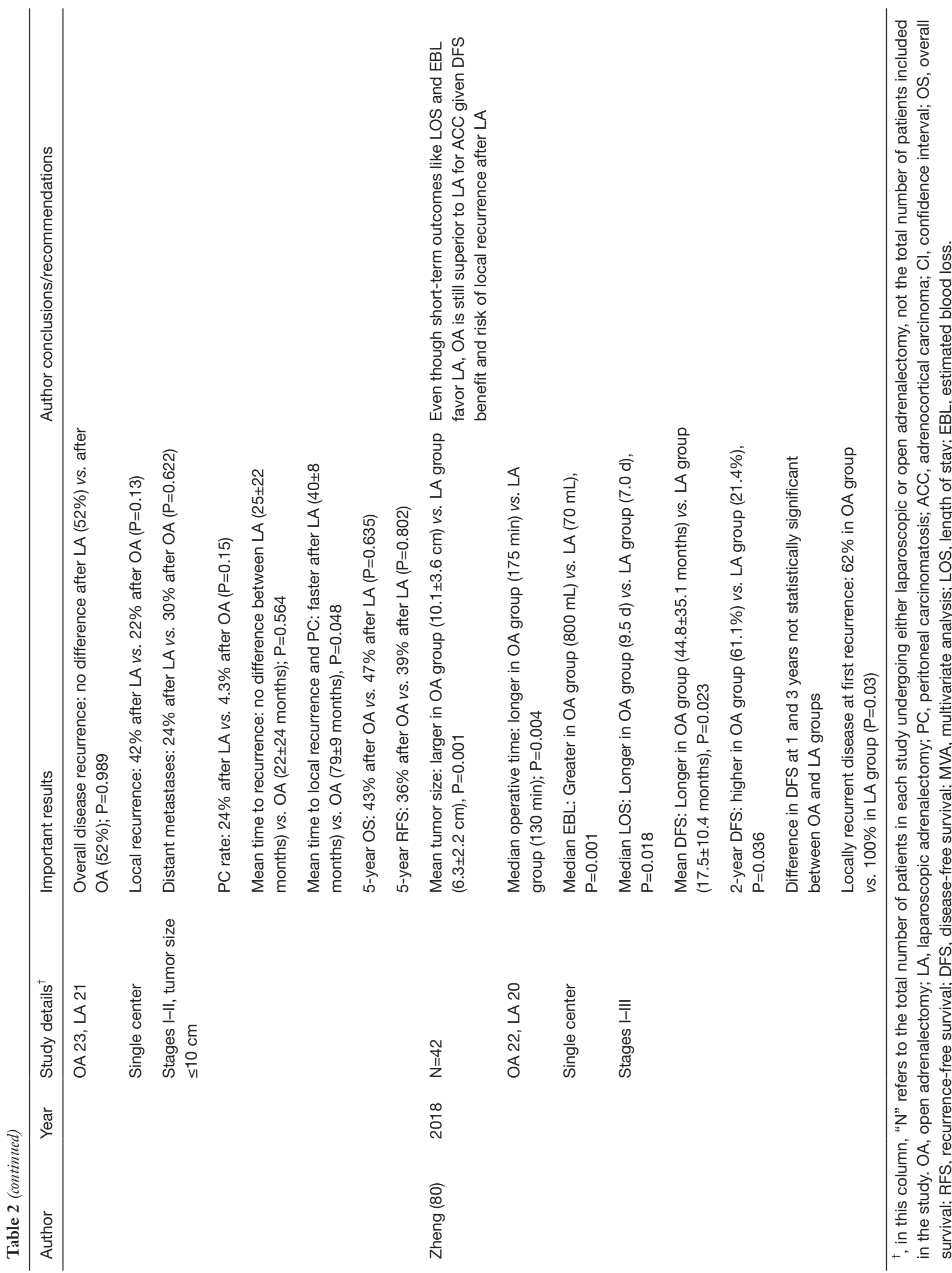

tᄒ

응 is

的

का

बำ

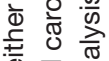

ब ब

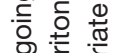

흥

品

总

它

$\subseteq$ 过

कृ के

要.

잉

잉

훙

है

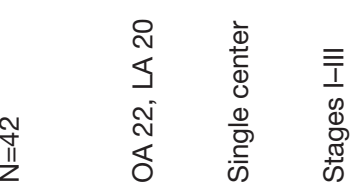

क्ञाँ

Q 율

워

क

क्ष

흥

ธี

言

0 을 ㄸ

哜 के

$\subseteq \stackrel{\Phi}{=}$

$\therefore \subseteq$ 
in the OA group, outcomes between the two groups were similar, with no significant differences in overall 2-year overall or RFS. When adjustments were made for clinical stage, overall and disease-free survival benefits trended in favor of OA, but did not reach statistical significance (HR for recurrence $0.4,95 \% \mathrm{CI}, 0.2-1.2, \mathrm{P}=0.099$; HR for OS $0.5,95 \%$ CI, $0.2-1.2, \mathrm{P}=0.122$ ).

A larger retrospective analysis published by Cooper et al. in 2013 found long-term outcomes that favored OA over LA for patients with ACC (73). This study evaluated 302 patients with all stages of ACC. Two hundred ten underwent $\mathrm{OA}$ at outside centers, 46 underwent $\mathrm{OA}$ at the index hospital, and 46 underwent LA (all at outside centers). Median tumor size was larger in the OA versus LA groups (8.0 $\mathrm{cm}$ in LA group, $12.0 \mathrm{~cm}$ in OA group from outside hospitals, and $12.3 \mathrm{~cm}$ in OA group from index hospital). In this study, peritoneal carcinomatosis occurred in $54.3 \%$ of patients after undergoing LA, $27.6 \%$ after OA at an outside hospital, and $19.6 \%$ after OA at the index hospital $(\mathrm{P}=0.006)$. Additionally, RFS and OS were superior to LA when the authors controlled for clinical stage $(\mathrm{P}<0.0001$ for both). Similar to Miller et al. (77), the authors of this paper concluded that patients should undergo OA if they have an adrenal tumor suspected to be ACC (73).

The largest study comparing open versus laparoscopic adrenalectomy for suspected ACC was published by Huynh et al. in 2016 (74). Records of 423 patients who had undergone OA (286 patients) or LA (137 patients) for stages I-III ACC were identified from the National Cancer Center Database. Despite patients in the OA group having larger, more advanced tumors compared to the LA group, LA was identified as an independent risk factor for death on multivariate analysis (HR 1.86, 95\% CI, 1.02-3.38; $\mathrm{P}=0.04$ ). For patients with $\mathrm{T} 33$ tumors, the positive margin rate was significantly higher in the LA group compared to the OA group (54.6\% versus $21.7 \%, \mathrm{P}=0.0009)$. Although LA was associated with a significant increase in positive margin rate, surgical approach was not directly associated with OS in the overall cohort. For patients with T2 tumors, OS was better for OA compared to LA $(\mathrm{P}=0.04)$. The authors concluded that because OS may decrease in some patients with ACC treated with LA, "caution should still be used in selecting LA for surgical treatment of ACC” (74).

Two more retrospective studies were published in 2018. Zheng et al. reported retrospective data on 42 patients (22 OA versus $20 \mathrm{LA}$ ) with stages I-III ACC (80). Similar to previous studies, median tumor size was significantly larger in the OA group compared to the LA group. In this study, short-term metrics were evaluated in addition to longerterm outcomes. Although the short-term data, such as intra-operative blood loss, operative time, and length of stay all favored LA, long-term data favored OA. Mean DFS was significantly longer in the OA group compared to the LA group (44.8 \pm 35.1 versus $17.5 \pm 10.4$ months, $\mathrm{P}=0.023$ ).

Later in 2018, Wu et al. published data on 44 patients who had undergone OA (23 patients) or LA (21 patients) for stages I-II ACC with tumor size less than $10 \mathrm{~cm}$ (79). Mean duration of post-operative hospital stay was shorter after LA versus $\mathrm{OA}$ by an average of 3 days (6 versus 9 days, $\mathrm{P}=0.002)$. Rates of local recurrence $(42 \%$ versus $22 \%, \mathrm{P}=0.13)$ and peritoneal carcinomatosis $(24 \%$ versus $4.3 \%, \mathrm{P}=0.15$ ) trended in favor of OA but did not reach statistical significance. However, mean time to local recurrence and peritoneal carcinomatosis was significantly shorter in the LA group compared to the OA group ( $40 \pm 8$ versus $79 \pm 9$ months, $\mathrm{P}=0.048)$. Five-year overall ( $43 \%$ after $\mathrm{OA}$ versus $47 \%$ after $\mathrm{LA}, \mathrm{P}=0.635$ ) and risk-free survival (36\% after OA versus $39 \%$ after $\mathrm{LA}, \mathrm{P}=0.802$ ) was similar between groups.

A meta-analysis published by Autorino et al. in 2016 examined nine retrospective case-controlled studies published between 2010 and 2014 (240 total patients underwent LA, 557 patients underwent OA) (86). No differences were found in metrics such as overall recurrence (relative risk $1.09,95 \% \mathrm{CI}, 0.83-1.43, \mathrm{P}=0.52$ ), time to recurrence (weight mean difference -8.2 months, $95 \% \mathrm{CI}$, -18.2-1.7 months, $\mathrm{P}=0.11$ ), or cancer-specific mortality (odds ratio 0.68, 95\% CI, 0.44-1.05, $\mathrm{P}=0.08$ ) when comparing LA to OA. Peritoneal carcinomatosis occurred more often in the LA group compared to the OA group (RR 2.39; 95\% CI, 1.41-4.04; $\mathrm{P}=0.001$ ). The results of this meta-analysis led the authors to conclude that while LA has short-term benefits of shorter length of stay and recovery time, OA should be considered the standard of care in adrenal tumors suspected of being ACC, with LA reserved for carefully selected patients in centers with high expertise.

\section{Studies in which the data favor laparoscopic adrenalectomy}

In order for LA to supplant OA as standard of care for surgical resection of suspected ACC, it must demonstrate long-term oncologic outcomes comparable to OA while providing short-term benefits inherent to the minimally invasive approach. Case reports and case series from 1999 to 2005 detailed technical efficacy using laparoscopy to 
treat ACC (27-31). Since then, results of some retrospective analyses directly comparing laparoscopic versus the open adrenalectomy have concluded that LA is a feasible option for patients with ACC, particularly in carefully selected cases (Table 3) $(24,81-85,87,88)$.

In 2008, Kirshtein et al. published data on 12 patients who had undergone adrenalectomy for stages I-III ACC at a single institution (82). Seven underwent $\mathrm{OA}$ and 5 underwent LA. No recurrences were reported at the time of publication in either group, through the length of follow-up was not reported. Given the short-term benefits in the laparoscopic group (lower estimated blood loss and shorter length of stay), the authors deemed LA as a viable option for carefully selected patients with ACC based on short-term data.

Porpiglia et al. reported on 43 patients (25 OA, $18 \mathrm{LA})$ who underwent adrenalectomy for stages III ACC at multiple surgical centers (88). In this series, baseline demographics were similar between groups, with no statistically significant differences in median age $(41.3$ versus $47, \mathrm{P}=0.16$ ), tumor stage ( $88 \%$ stage $\mathrm{I}$ versus $80 \%$ stage II, $\mathrm{P}=0.4)$, or median tumor size $(10.5$ versus $9 \mathrm{~cm}$, $\mathrm{P}=0.39$ ) in the open versus laparoscopic groups. Recurrence occurred in $50 \%$ of patients undergoing LA compared to $64 \%$ of patients undergoing OA. Median RFS was similar in the OA group versus the LA group (18 versus 23 months, $\mathrm{P}=0.8$ ). Mortality during follow-up trended in favor of LA (5\%) compared to OA (28\%). The authors concluded that LA was feasible in the management of ACC, but did not definitively confirm its efficacy.

Brix et al. analyzed data from a larger group of patients derived from a German registry of ACC patients undergoing OA or LA for stages I-III ACC less than $10 \mathrm{~cm}$ (81). Out of the 152 patients included in the study, 117 underwent $\mathrm{OA}$ and 35 underwent LA. The occurrence of peritoneal carcinomatosis was $3 \%$ in both groups. No differences between groups were seen regarding diseasespecific survival (HR for death 0.98, 95\% CI, 0.51-1.92, $\mathrm{P}=0.92$ on MVA) and adjusted RFS (HR 0.91, 95\% CI, $0.56-1.46, \mathrm{P}=0.69)$. Importantly, 12 out of 35 patients undergoing LA required conversion to an open procedure, although the authors reported no differences in the outcomes of the converted patients compared to patients whose surgeries were entirely laparoscopic.

Lombardi et al. reported data from multiple centers in 2012 on 156 patients who underwent OA $(n=126)$ or LA $(\mathrm{n}=30)$ for stages I-II ACC (84). Rates of local recurrence were similar after OA and LA (19\% versus $21 \%$ ), with rates of distant metastases trending in favor of LA (31\% after
OA, $17 \%$ after LA; P>0.05) over a mean follow-up time of $42 \pm 35$ months. Mean time to recurrence was also similar between groups, and 5-year disease-free survival trended in favor of the LA group (38.3\% after OA versus $58.2 \%$ after LA; $>>0.05$ ).

In 2013, Fossa et al. reported outcomes on 32 patients from a single institution who underwent $\mathrm{OA}(\mathrm{n}=15)$ or LA $(n=17)$ for stages I-III ACC. Short-term benefits favored the LA group including median operative time (150 for LA versus $230 \mathrm{~min}$ for $\mathrm{OA}, \mathrm{P}=0.005)$, median number of perioperative transfusions ( 0 units for LA versus 3 units for OA, $\mathrm{P}=0.04$ ), median length of stay (6 days after LA versus 13 days after $\mathrm{OA}, \mathrm{P}<0.001)$, and median estimated blood loss ( $<400$ during LA versus $1,700 \mathrm{~mL}$ during OA, $\mathrm{P}<0.001)$. Of note, median tumor size was significantly larger in the OA group $(13.0 \mathrm{~cm}$ in the $\mathrm{OA}$ group versus $8.0 \mathrm{~cm}$ in the LA group, $\mathrm{P}=0.002$ ), which could account for some of the short-term differences. R0 resection rates were similar in both groups ( $80 \%$ after OA versus $71 \%$ after LA). Recurrence rates were high and similar in both groups ( $88 \%$ after OA versus $80 \%$ after LA). Median progression-free survival approached statistical significance in favor of LA (15.2 months after LA versus 8.1 months after $\mathrm{OA}, \mathrm{P}=0.057$ ), although this was not derived from a multivariable model. The authors proposed that because rates of early recurrence were high and similar regardless of the surgical approach, short-term benefits of LA such as length of stay and intraoperative blood loss should factor into decision-making.

Donatini and colleagues evaluated outcomes from patients who had undergone LA $(n=13)$ or OA $(n=21)$ for stages I-II ACC less than $10 \mathrm{~cm}$ at a single center (24). They reported $\mathrm{R} 0$ resection status in all patients, and found no differences in overall survival ( $81 \%$ versus $85 \%, \mathrm{P}=0.634$ ), recurrence rate $(24 \%$ versus $31 \%, \mathrm{P}=0.655)$, or disease-free survival (47 versus 46 months, $\mathrm{P}=0.893$ ) between $\mathrm{OA}$ and LA groups at comparable median follow-up times. Reported short-term outcomes included a significantly shorter length of stay after LA, and similar surgical complication rates between the two groups ( $8 \%$ in LA group versus $14 \%$ in OA group, $\mathrm{P}=0.387$ ).

Maurice et al. used the National Cancer Database to compare outcomes for patients with stages I-IV ACC undergoing OA $(\mathrm{n}=320)$ versus minimally invasive adrenalectomy (MIA; 131 laparoscopic, 30 robotic) (85). Benefits of a minimally invasive approach included shorter median length of stay (LOS) ( 3 versus 6 days, $\mathrm{P}<0.01$ ) and a lower re-admission rate $(4.4 \%$ versus $8.8 \%, \mathrm{P}=0.08)$. 

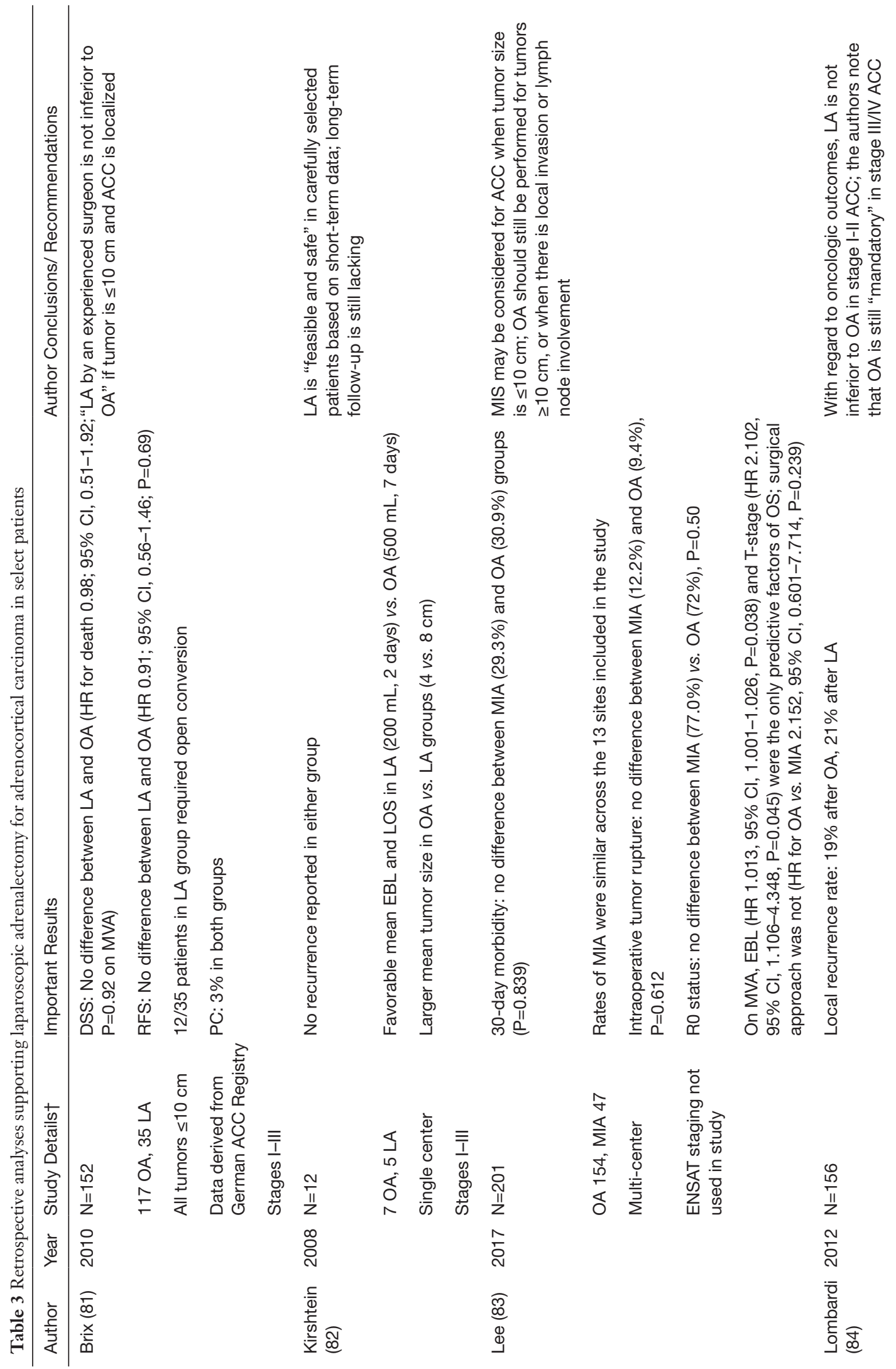

ํํำ 음

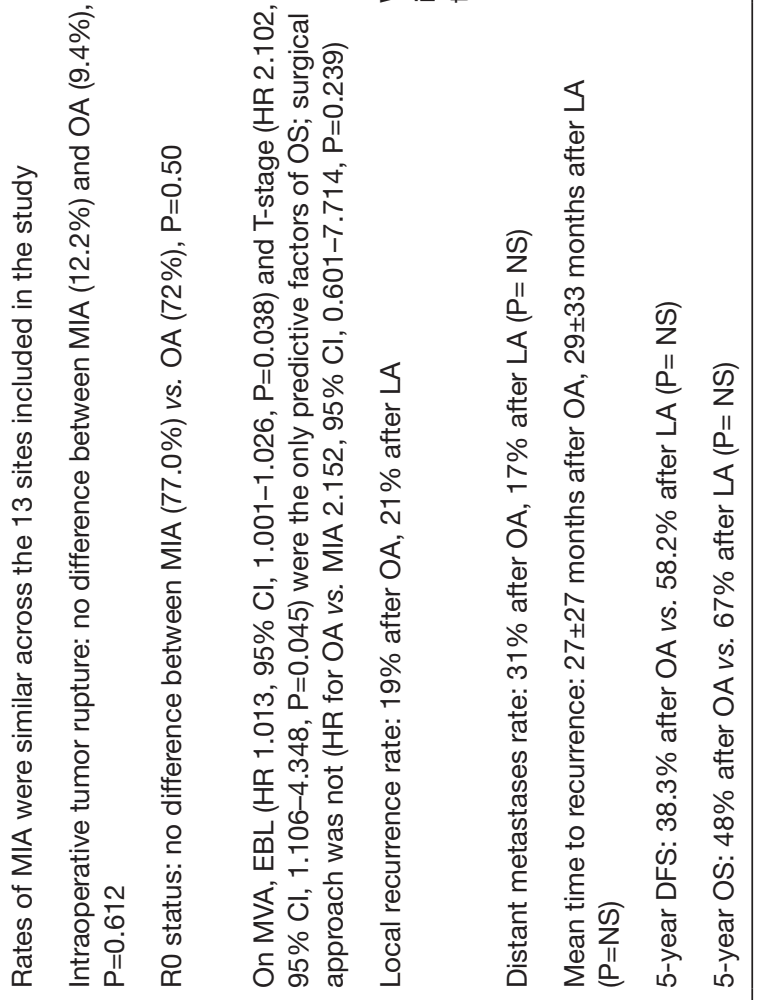

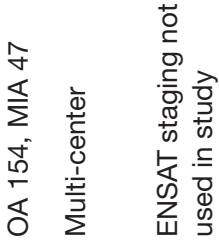

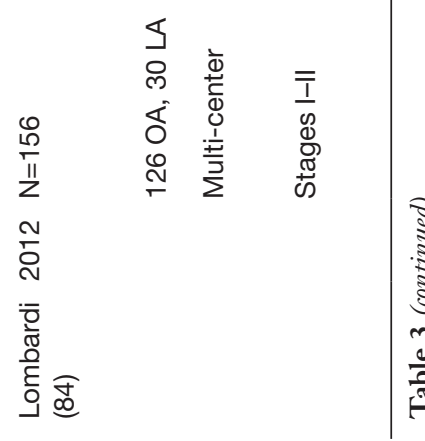




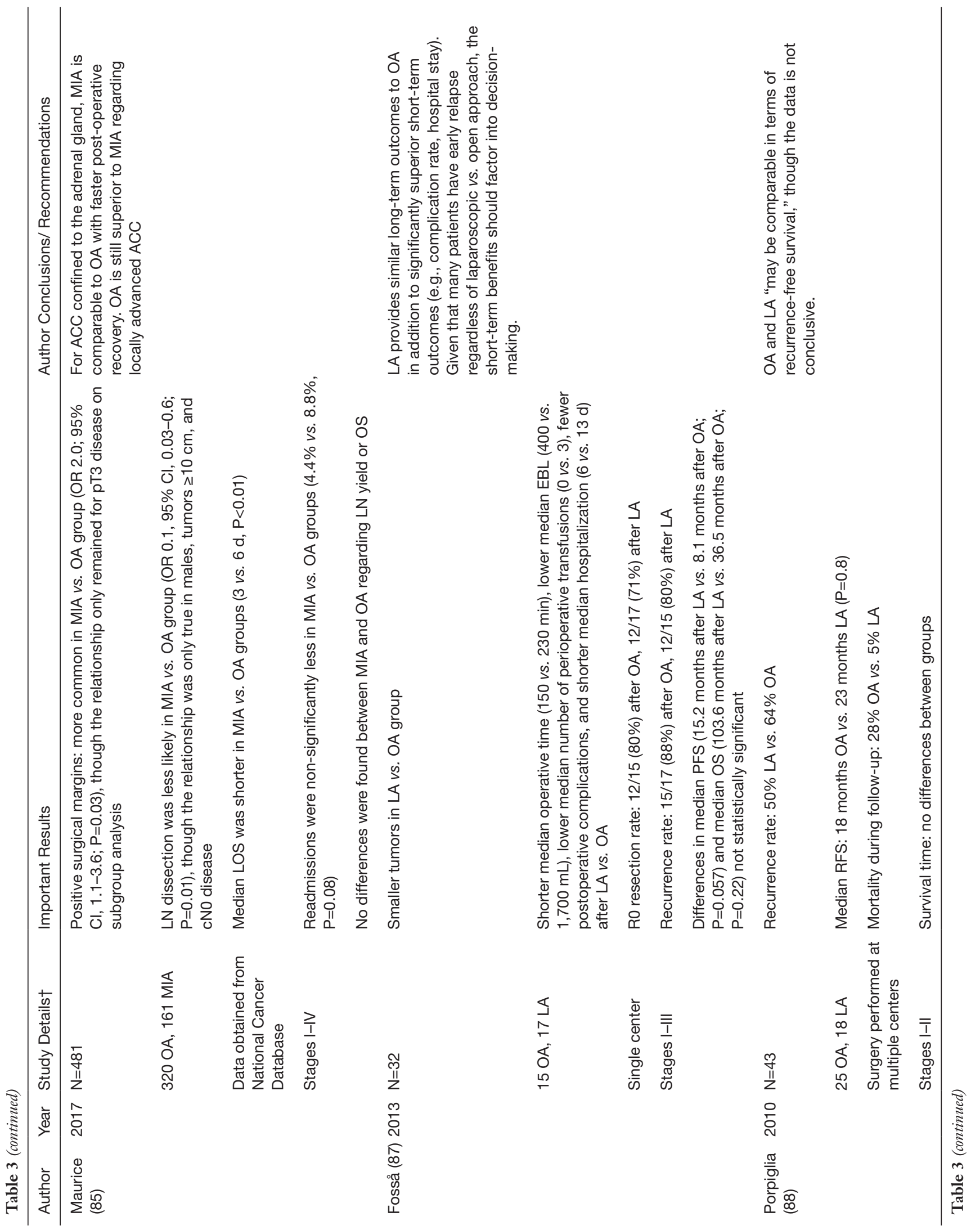



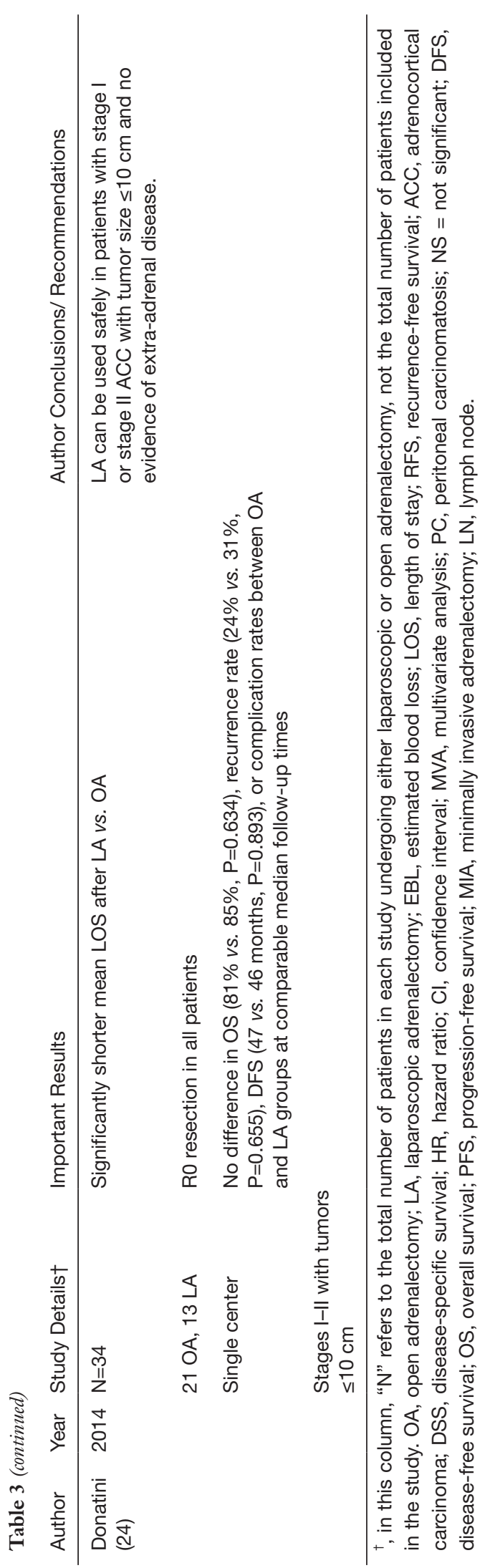

Positive surgical margins were more common in the minimally invasive versus open group (OR 2.0; 95\% CI, 1.1-3.6; $\mathrm{P}=0.03)$; subgroup analyses demonstrated this was due to the patients with pT3 or greater disease. No statistically significant differences in 3-year OS were found between MIA and $\mathrm{OA}(58.0 \%$ versus $62.1 \%, \mathrm{P}=0.42)$ on univariable analysis; adjusted analysis yielded a $\mathrm{P}$ value of 0.05 , which did not meet the authors' pre-set criteria for significance of $\mathrm{P}<0.05$. The authors concluded that MIA provides acceptable long-term outcomes with faster postoperative recovery for patients with Stage I-II ACC.

Finally, Lee and colleagues retrospectively examined 201 patients from multiple centers $(n=154$ for OA and $n=47$ for MIA) (83). Importantly, ENSAT staging was not incorporated into this study. This study found no difference in 30-day mortality between the MIA group $(29.3 \%)$ versus the OA group $(30.9 \%), \mathrm{P}=0.839$. Intraoperative tumor rupture did not occur more frequently in the minimally invasive versus open groups $(12.2 \%$ versus $9.4 \%, \mathrm{P}=0.612)$ and $\mathrm{R} 0$ status was achieved in a comparable number of patients $(77.0 \%$ after MIA versus $72 \%$ after $\mathrm{OA}$ ), $\mathrm{P}=0.50$ ). Estimated blood loss (HR 1.013, 95\% CI, 1.001-1.026, P=0.038) and T stage (T3T4 versus T1-T2: HR 2.102, 95\% CI, 1.106-4.348, $\mathrm{P}=0.045$ ) were predictive of survival, whereas surgical approach was not (HR for OA versus MIA 2.152, 95\% CI, 0.601-7.714, $\mathrm{P}=0.239)$ on multivariable analysis. The authors concluded that MIA can be considered in patients with localized tumors less than or equal to $10 \mathrm{~cm}$.

\section{Discussion}

Current ESES and ENSAT guidelines strongly recommend $\mathrm{OA}$ as the standard of care surgical approach for patients with suspected ACC (19). While there is cautious acknowledgement of LA as an option in carefully selected patients with suspected ACC, the panel recommends against LA for all cases of stage III or stage IV ACC. For suspected ACC less than $6 \mathrm{~cm}$ and confined to the adrenal gland (stage I or II), the panel states that LA is an option, but should be undertaken only in high-volume centers. Notably, the panel agreement was low, the strength of the recommendation was weak, and the evidence level supporting LA was rated as very low. Lastly, the necessity of respecting the principles of oncological surgery is emphasized with a low threshold for open conversion if a risk of tumor spillage or capsular disruption is encountered. Notably, the National Comprehensive Cancer Network also recommends OA even for localized ACC, citing "increased 
risk for local recurrence and peritoneal spread when done laparoscopically" (21).

When evaluating data from retrospective analyses, it is important to consider their results in the context of any limitations inherent to their study designs. The lack of randomization allows for between-group differences. Indeed, many of the studies comparing OA to LA report significant differences in factors such as patient age, tumor size, and stage at diagnosis. Since they are not controlled nor randomized trials, retrospective studies are prone to confounding errors, in which factors other than the intervention in question affect the outcome under investigation.

Because ACC is exceedingly rare, and because it is only definitively diagnosed on post-resection or autopsy histology, studies evaluating treatment options for ACC are exclusively retrospective. Although all retrospective studies are subject to the errors and biases listed above, each does not control for potential sources of unintended influence with equal success. Furthermore, surface-level consideration of studies published on open versus laparoscopic outcomes for ACC appear to show a similar number of studies landing on either side of the debate; critical analysis of the quality of these studies is therefore paramount in determining which data best approximates an unbiased truth.

Despite any degree of control that some studies attempted to employ, many had results whose generalizability was limited by a small or unbalanced patient population or limited long-term follow-up $(24,73,75,77,78,81,84,87,88)$, a fact acknowledged by the current ESES and ENSAT guidelines (19). In ten studies (24,70,75,76,78,80,82,87-89), 20 or fewer patients were included in one or both of the surgical groups and seven studies included fewer than 50 patients total $(24,78-80,82,87,88)$. Considering the small number of total patients studied, meta-analyses are one way to bolster otherwise equivocal data. Autorino et al. were able to pool results from 9 studies that directly compared LA (240 cases) to OA (557 cases), with each study including a minimum of 10 cases performed via each approach (86). Selection biases that plagued individual studies additionally manifested in this pooled analysis, with significantly smaller tumors seen in the LA group versus the OA group (weight mean difference $-3.41 \mathrm{~cm}, \mathrm{P}<0.001$ ). Although no differences in recurrence rates, time to recurrence, or cancer specific mortality were seen between groups, patients who underwent LA did have significantly higher rates of peritoneal carcinomatosis. The finding that increased rates of peritoneal carcinomatosis after LA persisted despite ACCs being significantly larger in the $\mathrm{OA}$ group lends credibility to the likelihood that this is a true association.

Studies that included larger numbers of patients were also subject to confounding. Maurice et al. examined data on 481 patients from the National Cancer Database, the largest sample size of all studies comparing LA $(n=161)$ and OA ( $n=320)$ for ACC (85). The authors concluded that MIA was appropriate for ACC confined to the adrenal gland. However, statistically significant differences were present in baseline demographics and tumor characteristics including age, Charlson Comorbidity Index, tumor size, T-stage, and whether or not the surgery was performed at a high-volume center; clinical $\mathrm{N}$-stage approached significance in favor of MIA $(\mathrm{P}=0.08)$. Though the authors found no difference in 3 -year OS between patients undergoing MIA (58.0\%) versus OA (62.1\%) with $\mathrm{P}=0.42$, this difference favoring $\mathrm{OA}$ trended towards statistical significance on adjusted analysis $(\mathrm{P}=0.05)$.

An important finding from Miller et al. also calls into question the true accuracy of data collected on outcomes of ACC patients (77). In this study, 13 of 40 patients (30\%) with ACC considered pre-operatively to be stage II were upstaged postoperatively to stage III after undergoing LA; this trend held true for patients undergoing OA, with 22 of $71(31 \%)$ pre-operative stage II patients upstaged to stage III ACC postoperatively. Importantly, in these upstaged patients, $75 \%$ of patients in the LA group had positive margins versus only $36 \%$ in the OA group, leading the authors to state that more complete resection is achieved with an open versus laparoscopic approach. The implication of these data is important because any study concluding that a threshold of stage II disease or no local invasion should be used in determining when to employ LA $(24,81,83-85)$ will have to reconcile the fact that $30 \%$ of these tumors may in fact be stage III at surgical resection.

In addition, volume-outcome relationships seen in other major cancer surgeries have been suggested to influence adrenalectomy for suspected ACC (90). One study stratified patients by both procedure type (OA versus LA) and location of surgery (referring hospital versus index hospital) found significant differences between the same type of surgery (OA) performed at a referring hospital versus the index hospital. This included important measures such as R0 margin status (44.3\% after OA at referring hospital versus $89.1 \%$ after OA at index hospital) and peritoneal carcinomatosis $(27.6 \%$ after OA at referring hospital versus $19.6 \%$ after OA at index hospital) (73). Therefore, where these surgeries are done may greatly influence patient outcomes.

Given that ACC is uncommon and rarely diagnosed pre- 
operatively, it is unlikely that a randomized trial of OA versus LA for suspected ACC will ever be conducted. Therefore, we are limited to well-controlled observational studies on which to make treatment recommendations. The priority of any cancer surgery is oncologic control. Given the aggressive nature, poor prognosis, and lack of effective systemic treatment options for ACC, complete surgical resection is the best chance to cure these patients. There is a signal that LA may result in greater likelihood of a positive surgical margin and an increased risk of peritoneal carcinomatosis. Both of these events are uniformly fatal. Therefore, we should not allow surgical hubris to overshadow the underlying aggressive biology of ACC and potentially compromise outcomes for these patients: simply because we can perform LA for ACC does not necessarily mean that we should.

\section{Conclusions}

A prospective, randomized clinical trial comparing LA to OA for ACC is unlikely to be performed. Therefore, well-controlled observational studies remain the highest level of evidence to support surgical decision-making in patients with suspected ACC. OA is the definitive surgical standard of care for stages III and IV ACC. While data are less clear for clinical Stage I and II ACC, the risk of pathologic upstaging, tumor spillage, and positive surgical margin status cannot be understated since the latter two are uniformly fatal. Therefore, current guidelines across the world recommend OA for all patients with adrenal tumors suspicious for ACC.

\section{Acknowledgments}

Funding: None.

\section{Footnote}

Provenance and Peer Review: This article was commissioned by the Guest Editors (Marc C. Smaldone and Jeffrey J. Tomaszewski) for the series "Controversies in Minimally Invasive Urologic Oncology" published in Translational Andrology and Urology. The article has undergone external peer review.

Conflicts of Interest: All authors have completed the ICMJE uniform disclosure form (available at http://dx.doi. org/10.21037/tau.2020.01.11). The series "Controversies in Minimally Invasive Urologic Oncology” was commissioned by the editorial office without any funding or sponsorship. The authors have no other conflicts of interest to declare.

Ethical Statement: The authors are accountable for all aspects of the work in ensuring that questions related to the accuracy or integrity of any part of the work are appropriately investigated and resolved.

Open Access Statement: This is an Open Access article distributed in accordance with the Creative Commons Attribution-NonCommercial-NoDerivs 4.0 International License (CC BY-NC-ND 4.0), which permits the noncommercial replication and distribution of the article with the strict proviso that no changes or edits are made and the original work is properly cited (including links to both the formal publication through the relevant DOI and the license). See: https://creativecommons.org/licenses/by-nc-nd/4.0/.

\section{References}

1. Nieman LK. Approach to the patient with an adrenal incidentaloma. J Clin Endocrinol Metab 2010;95:4106-13.

2. Saunders BD, Doherty GM. Laparoscopic adrenalectomy for malignant disease. Lancet Oncol 2004;5:718-26.

3. Berruti A, Baudin E, Gelderblom H, et al. Adrenal cancer: ESMO Clinical Practice Guidelines for diagnosis, treatment and follow-up. Ann Oncol 2012;23 Suppl 7:vii131-8.

4. Koschker AC, Fassnacht M, Hahner S, et al. Adrenocortical carcinoma -- improving patient care by establishing new structures. Exp Clin Endocrinol Diabetes 2006;114:45-51.

5. Zini L, Porpiglia F, Fassnacht M. Contemporary management of adrenocortical carcinoma. Eur Urol 2011;60:1055-65.

6. Abiven G, Coste J, Groussin L, et al. Clinical and biological features in the prognosis of adrenocortical cancer: poor outcome of cortisol-secreting tumors in a series of 202 consecutive patients. J Clin Endocrinol Metab 2006;91:2650-5.

7. Libè R, Fratticci A, Bertherat J. Adrenocortical cancer: pathophysiology and clinical management. Endocr Relat Cancer 2007;14:13-28.

8. Canter DJ, Mallin K, Uzzo RG, et al. Association of tumor size with metastatic potential and survival in patients with adrenocortical carcinoma: an analysis of the National Cancer Database. Can J Urol 2013;20:6915-21.

9. NIH state-of-the-science statement on management of the 
clinically inapparent adrenal mass ("incidentaloma"). NIH Consens State Sci Statements 2002;19:1-25.

10. Sturgeon C, Shen WT, Clark OH, et al. Risk assessment in 457 adrenal cortical carcinomas: how much does tumor size predict the likelihood of malignancy? J Am Coll Surg 2006;202:423-30.

11. Abdel-Aziz TE, Rajeev P, Sadler G, et al. Risk of adrenocortical carcinoma in adrenal tumours greater than $8 \mathrm{~cm}$. World J Surg 2015;39:1268-73.

12. Zeiger MA, Thompson GB, Duh QY, et al. The American Association of Clinical Endocrinologists and American Association of Endocrine Surgeons medical guidelines for the management of adrenal incidentalomas. Endocr Pract 2009;15 Suppl 1:1-20.

13. Boland GW, Lee MJ, Gazelle GS, et al. Characterization of adrenal masses using unenhanced CT: an analysis of the CT literature. AJR Am J Roentgenol 1998;171:201-4.

14. Zhang HM, Perrier ND, Grubbs EG, et al. CT features and quantification of the characteristics of adrenocortical carcinomas on unenhanced and contrast-enhanced studies. Clin Radiol 2012;67:38-46.

15. Petersenn S, Richter PA, Broemel T, et al. Computed tomography criteria for discrimination of adrenal adenomas and adrenocortical carcinomas: analysis of the German ACC registry. Eur J Endocrinol 2015;172:415-22.

16. Szolar DH, Kammerhuber FH. Adrenal adenomas and nonadenomas: assessment of washout at delayed contrastenhanced CT. Radiology 1998;207:369-75.

17. Blake MA, Kalra MK, Sweeney AT, et al. Distinguishing benign from malignant adrenal masses: multi-detector row CT protocol with 10-minute delay. Radiology 2006;238:578-85.

18. Park BK, Kim CK, Kim B, et al. Comparison of delayed enhanced CT and chemical shift MR for evaluating hyperattenuating incidental adrenal masses. Radiology 2007;243:760-5

19. Gaujoux S, Mihai R, joint working group of ESES and ENSAT. European Society of Endocrine Surgeons (ESES) and European Network for the Study of Adrenal Tumours (ENSAT) recommendations for the surgical management of adrenocortical carcinoma. Br J Surg 2017;104:358-76.

20. Fassnacht M, Johanssen S, Quinkler M, et al. Limited prognostic value of the 2004 International Union Against Cancer staging classification for adrenocortical carcinoma: proposal for a Revised TNM Classification. Cancer 2009; 115:243-50.

21. Shah MH, Kulke MH, Goldner WS, et al. NCCN Clinical
Practice Guidelines in Oncology (NCCN Guidelines)

Neuroendocrine and Adrenal Tumors. Version 4.2018.

National Comprehensive Cancer Network; 2018. Available online: https://www.nccn.org/professionals/physician_gls/ pdf/neuroendocrine.pdf

22. Lughezzani G, Sun M, Perrotte P, et al. The European Network for the Study of Adrenal Tumors staging system is prognostically superior to the international union against cancer-staging system: a North American validation. Eur J Cancer 2010;46:713-9.

23. Low G, Sahi K. Clinical and imaging overview of functional adrenal neoplasms. Int J Urol 2012;19:697-708.

24. Donatini G, Caiazzo R, Do Cao C, et al. Long-term survival after adrenalectomy for stage I/II adrenocortical carcinoma (ACC): a retrospective comparative cohort study of laparoscopic versus open approach. Ann Surg Oncol 2014;21:284-91.

25. Gaujoux S, Pinson S, Gimenez-Roqueplo AP, et al. Inactivation of the APC gene is constant in adrenocortical tumors from patients with familial adenomatous polyposis but not frequent in sporadic adrenocortical cancers. Clin Cancer Res 2010;16:5133-41.

26. Raymond VM, Everett JN, Furtado LV, et al. Adrenocortical carcinoma is a lynch syndrome-associated cancer. J Clin Oncol 2013;31:3012-8.

27. Hisada M, Garber JE, Fung CY, et al. Multiple primary cancers in families with Li-Fraumeni syndrome. J Natl Cancer Inst 1998;90:606-11.

28. Choufani S, Shuman C, Weksberg R. BeckwithWiedemann syndrome. Am J Med Genet C Semin Med Genet 2010;154C:343-54.

29. Arlt W, Biehl M, Taylor AE, et al. Urine steroid metabolomics as a biomarker tool for detecting malignancy in adrenal tumors. J Clin Endocrinol Metab 2011;96:3775-84.

30. Ilias I, Sahdev A, Reznek RH, et al. The optimal imaging of adrenal tumours: a comparison of different methods. Endocr Relat Cancer 2007;14:587-99.

31. Groussin L, Bonardel G, Silvera S, et al 18F-Fluorodeoxyglucose positron emission tomography for the diagnosis of adrenocortical tumors: a prospective study in 77 operated patients. J Clin Endocrinol Metab 2009;94:1713-22.

32. Tessonnier L, Ansquer C, Bournaud C, et al. (18)F-FDG uptake at initial staging of the adrenocortical cancers: a diagnostic tool but not of prognostic value. World J Surg 2013;37:107-12. 
33. Shulkin BL, Thompson NW, Shapiro B, et al. Pheochromocytomas: imaging with 2-[fluorine-18]fluoro2-deoxy-D-glucose PET. Radiology 1999;212:35-41.

34. Minn H, Salonen A, Friberg J, et al. Imaging of adrenal incidentalomas with PET using (11)C-metomidate and (18)F-FDG. J Nucl Med 2004;45:972-9.

35. Kreissl MC, Schirbel A, Fassnacht M, et al. [I] Iodometomidate imaging in adrenocortical carcinoma. J Clin Endocrinol Metab 2013;98:2755-64.

36. Carnaille B. Adrenocortical carcinoma: which surgical approach? Langenbecks Arch Surg 2012;397:195-9.

37. Else T, Kim AC, Sabolch A, et al. Adrenocortical carcinoma. Endocr Rev 2014;35:282-326.

38. Grubbs EG, Callender GG, Xing Y, et al. Recurrence of adrenal cortical carcinoma following resection: surgery alone can achieve results equal to surgery plus mitotane. Ann Surg Oncol 2010;17:263-70.

39. Bilimoria KY, Shen WT, Elaraj D, et al. Adrenocortical carcinoma in the United States: treatment utilization and prognostic factors. Cancer 2008;113:3130-6.

40. Bellantone R, Lombardi CP, Raffaelli M. What is the appropriate role of minimally invasive vs. open surgery for small adrenocortical cancers? Curr Opin Oncol 2015;27:44-9.

41. Margonis GA, Kim Y, Prescott JD, et al. Adrenocortical Carcinoma: Impact of Surgical Margin Status on LongTerm Outcomes. Ann Surg Oncol 2016;23:134-41.

42. Schteingart DE, Doherty GM, Gauger PG, et al. Management of patients with adrenal cancer: recommendations of an international consensus conference. Endocr Relat Cancer 2005;12:667-80.

43. Scollo C, Russo M, Trovato MA, et al. Prognostic Factors for Adrenocortical Carcinoma Outcomes. Front Endocrinol (Lausanne) 2016;7:99.

44. Choi YM, Kwon H, Jeon MJ, et al. Clinicopathological Features Associated With the Prognosis of Patients With Adrenal Cortical Carcinoma: Usefulness of the Ki-67 Index. Medicine (Baltimore) 2016;95:e3736.

45. Shen WT, Sturgeon C, Duh QY. From incidentaloma to adrenocortical carcinoma: the surgical management of adrenal tumors. J Surg Oncol 2005;89:186-92.

46. Kendrick ML, Lloyd R, Erickson L, et al. Adrenocortical carcinoma: surgical progress or status quo? Arch Surg 2001;136:543-9.

47. Ramacciato G, Mercantini P, La Torre M, et al. Is laparoscopic adrenalectomy safe and effective for adrenal masses larger than $7 \mathrm{~cm}$ ? Surg Endosc 2008;22:516-21.
48. Tsuru N, Ushiyama T, Suzuki K. Laparoscopic adrenalectomy for primary and secondary malignant adrenal tumors. J Endourol 2005;19:702-8; discussion 708-9.

49. Amini N, Margonis GA, Kim Y, et al. Curative Resection of Adrenocortical Carcinoma: Rates and Patterns of Postoperative Recurrence. Ann Surg Oncol 2016;23:126-33.

50. Schulick RD, Brennan MF. Long-term survival after complete resection and repeat resection in patients with adrenocortical carcinoma. Ann Surg Oncol 1999;6:719-26.

51. Suzuki H. Laparoscopic adrenalectomy for adrenal carcinoma and metastases. Curr Opin Urol 2006;16:47-53.

52. Aspinall SR, Imisairi AH, Bliss RD, et al. How is adrenocortical cancer being managed in the UK? Ann R Coll Surg Engl 2009;91:489-93.

53. Kazaryan AM, Marangos IP, Rosseland AR, et al. Laparoscopic adrenalectomy: Norwegian single-center experience of 242 procedures. J Laparoendosc Adv Surg Tech A 2009;19:181-9.

54. Icard P, Goudet P, Charpenay C, et al. Adrenocortical carcinomas: surgical trends and results of a 253-patient series from the French Association of Endocrine Surgeons study group. World J Surg 2001;25:891-7.

55. Crucitti F, Bellantone R, Ferrante A, et al. The Italian Registry for Adrenal Cortical Carcinoma: analysis of a multiinstitutional series of 129 patients. The ACC Italian Registry Study Group. Surgery 1996;119:161-70.

56. Siegel R, Naishadham D, Jemal A. Cancer statistics, 2012. CA Cancer J Clin 2012;62:10-29.

57. Rossfeld KK, Maithel SK, Prescott J, et al. The prognostic significance of adrenocortical carcinomas identified incidentally. J Surg Oncol 2018;118:1155-62.

58. PDQ Cancer Information Summaries. Bethesda (MD): National Cancer Institute (US); 2002.

59. Michalakis K, Ilias I. Medical management of adrenal disease: a narrative review. Endocr Regul 2009;43:127-35.

60. Gagner M, Lacroix A, Prinz RA, et al. Early experience with laparoscopic approach for adrenalectomy. Surgery 1993;114:1120-4; discussion 1124-5.

61. Heniford BT, Arca MJ, Walsh RM, et al. Laparoscopic adrenalectomy for cancer. Semin Surg Oncol 1999;16:293-306.

62. MacGillivray DC, Whalen GF, Malchoff CD, et al. Laparoscopic resection of large adrenal tumors. Ann Surg Oncol 2002;9:480-5.

63. Henry JF, Sebag F, Iacobone M, et al. Results of laparoscopic adrenalectomy for large and potentially malignant tumors. World J Surg 2002;26:1043-7. 
64. Prager G, Heinz-Peer G, Passler C, et al. Applicability of laparoscopic adrenalectomy in a prospective study in 150 consecutive patients. Arch Surg 2004;139:46-9.

65. Moinzadeh A, Gill IS. Laparoscopic radical adrenalectomy for malignancy in 31 patients. J Urol 2005;173:519-25.

66. Ushiyama T, Suzuki K, Kageyama S, et al. A case of Cushing's syndrome due to adrenocortical carcinoma with recurrence 19 months after laparoscopic adrenalectomy. J Urol 1997;157:2239.

67. Foxius A, Ramboux A, Lefebvre Y, et al. Hazards of laparoscopic adrenalectomy for Conn's adenoma. When enthusiasm turns to tragedy. Surg Endosc 1999;13:715-7.

68. Hamoir E, Meurisse M, Defechereux T. Is laparoscopic resection of a malignant corticoadrenaloma feasible? Case report of early, diffuse and massive peritoneal recurrence after attempted laparoscopic resection. Ann Chir 1998;52:364-8.

69. Kebebew E, Siperstein AE, Clark OH, et al. Results of laparoscopic adrenalectomy for suspected and unsuspected malignant adrenal neoplasms. Arch Surg 2002;137:948-51; discussion 952-3.

70. Gonzalez RJ, Shapiro S, Sarlis N, et al. Laparoscopic resection of adrenal cortical carcinoma: a cautionary note. Surgery 2005;138:1078-85; discussion 1085-6.

71. Höfle G, Gasser RW, Lhotta K, et al. Adrenocortical carcinoma evolving after diagnosis of preclinical Cushing's syndrome in an adrenal incidentaloma. A case report. Horm Res 1998;50:237-42.

72. Deckers S, Derdelinckx L, Col V, et al. Peritoneal carcinomatosis following laparoscopic resection of an adrenocortical tumor causing primary hyperaldosteronism. Horm Res 1999;52:97-100.

73. Cooper AB, Habra MA, Grubbs EG, et al. Does laparoscopic adrenalectomy jeopardize oncologic outcomes for patients with adrenocortical carcinoma? Surg Endosc 2013;27:4026-32.

74. Huynh KT, Lee DY, Lau BJ, et al. Impact of Laparoscopic Adrenalectomy on Overall Survival in Patients with Nonmetastatic Adrenocortical Carcinoma. J Am Coll Surg 2016;223:485-92.

75. Leboulleux S, Deandreis D, Al Ghuzlan A, et al. Adrenocortical carcinoma: is the surgical approach a risk factor of peritoneal carcinomatosis? Eur J Endocrinol 2010;162:1147-53.

76. Miller BS, Ammori JB, Gauger PG, et al. Laparoscopic resection is inappropriate in patients with known or suspected adrenocortical carcinoma. World J Surg
2010;34:1380-5.

77. Miller BS, Gauger PG, Hammer GD, et al. Resection of adrenocortical carcinoma is less complete and local recurrence occurs sooner and more often after laparoscopic adrenalectomy than after open adrenalectomy. Surgery 2012;152:1150-7.

78. Mir MC, Klink JC, Guillotreau J, et al. Comparative outcomes of laparoscopic and open adrenalectomy for adrenocortical carcinoma: single, high-volume center experience. Ann Surg Oncol 2013;20:1456-61.

79. Wu K, Liu Z, Liang J, et al. Laparoscopic versus open adrenalectomy for localized (stage 1/2) adrenocortical carcinoma: Experience at a single, high-volumecenter. Surgery 2018;164:1325-9.

80. Zheng GY, Li HZ, Deng JH, et al. Open adrenalectomy versus laparoscopic adrenalectomy for adrenocortical carcinoma: a retrospective comparative study on short-term oncologic prognosis. Onco Targets Ther 2018;11:1625-32.

81. Brix D, Allolio B, Fenske W, et al. Laparoscopic versus open adrenalectomy for adrenocortical carcinoma: surgical and oncologic outcome in 152 patients. Eur Urol 2010;58:609-15.

82. Kirshtein B, Yelle JD, Moloo H, et al. Laparoscopic adrenalectomy for adrenal malignancy: a preliminary report comparing the short-term outcomes with open adrenalectomy. J Laparoendosc Adv Surg Tech A 2008;18:42-6.

83. Lee CW, Salem AI, Schneider DF, et al. Minimally Invasive Resection of Adrenocortical Carcinoma: a MultiInstitutional Study of 201 Patients. J Gastrointest Surg 2017;21:352-62.

84. Lombardi CP, Raffaelli M, De Crea C, et al. Open versus endoscopic adrenalectomy in the treatment of localized (stage I/II) adrenocortical carcinoma: results of a multiinstitutional Italian survey. Surgery 2012;152:1158-64.

85. Maurice MJ, Bream MJ, Kim SP, et al. Surgical quality of minimally invasive adrenalectomy for adrenocortical carcinoma: a contemporary analysis using the National Cancer Database. BJU Int 2017;119:436-43.

86. Autorino R, Bove P, De Sio M, et al. Open Versus Laparoscopic Adrenalectomy for Adrenocortical Carcinoma: A Meta-analysis of Surgical and Oncological Outcomes. Ann Surg Oncol 2016;23:1195-202.

87. Fosså A, Rosok BI, Kazaryan AM, et al. Laparoscopic versus open surgery in stage I-III adrenocortical carcinoma -- a retrospective comparison of 32 patients. Acta Oncol 
2013;52:1771-7.

88. Porpiglia F, Fiori C, Daffara F, et al. Retrospective evaluation of the outcome of open versus laparoscopic adrenalectomy for stage I and II adrenocortical cancer. Eur Urol 2010;57:873-8.

89. Simon G, Pattou F, Mirallie E, et al. Surgery for recurrent adrenocortical carcinoma: A multicenter retrospective study. Surgery 2017;161:249-56.

90. Birkmeyer JD, Siewers AE, Finlayson EV, et al. Hospital volume and surgical mortality in the United States. N Engl J Med 2002;346:1128-37.
Cite this article as: Buller DM, Hennessey AM, Ristau BT. Open versus minimally invasive surgery for suspected adrenocortical carcinoma. Transl Androl Urol 2021;10(5):2246-2263. doi: 10.21037/tau.2020.01.11 